\title{
Seismic Coda Waves
}

\author{
L. Margerin \\ CNRS, Toulouse, France
}

In collaboration with B. Van Tiggelen, M. Campillo, E. Larose, C. Sens-Schoenfelder, V.

Rossetto, N. Shapiro ...

Students: D. Anache-Ménier, T. Planès, A. Obermann 


\section{Seismic Coda Waves}

L. Margerin

CNRS, Toulouse, France

Mesoscopic physics in complex media

In collaboration with B. Van Tiggelen, M. Campillo, E. Larose, C. Sens-Schoenfelder, V.

Rossetto, N. Shapiro ...

Students: D. Anache-Ménier, T. Planès, A. Obermann 


\section{Content}

(1) Observation of seismic coda waves

(2) Equipartition of seismic waves

(3) Green function reconstruction

(4) Monitoring the Earth with coda waves

(5) Weak localization of seismic waves

(6) Phase statistics of coda waves 


\section{Content}

(1) Observation of seismic coda waves

(2) Equipartition of seismic waves

(3) Green function reconstruction

(4) Monitoring the Earth with coda waves

(5) Weak localization of seismic waves

(6) Phase statistics of coda waves 


\section{Crustal Coda Waves}
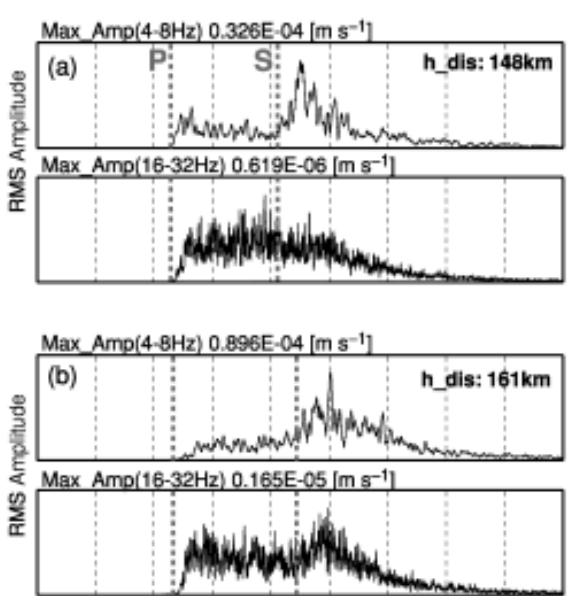

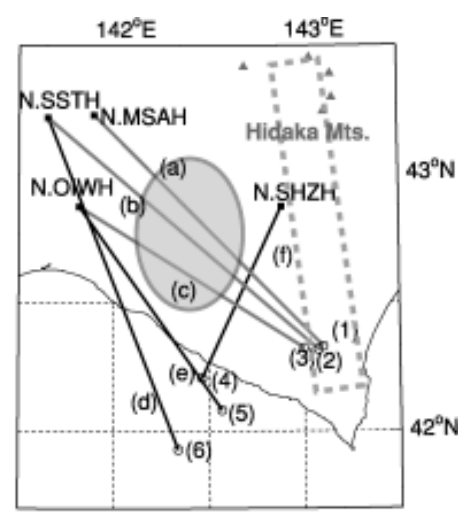

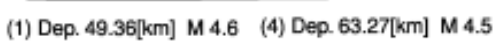

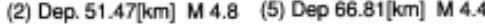

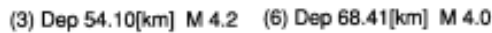
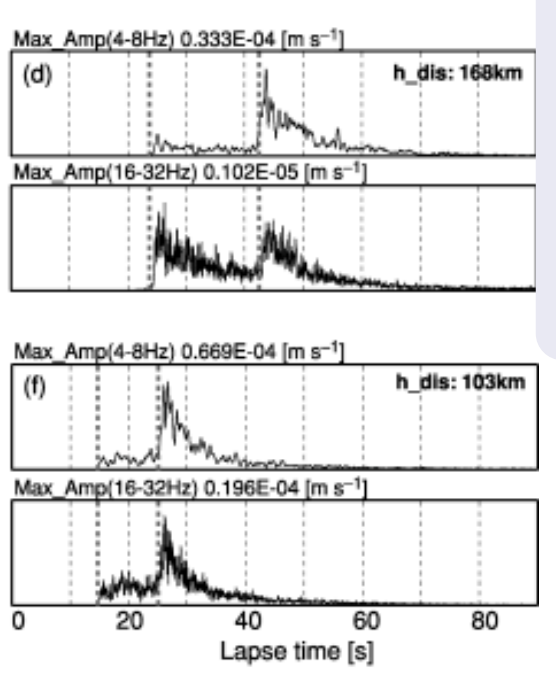

\section{Space and Time Scales}

- Frequency $>1 \mathrm{~Hz}$

- Wavelength $\sim$ tens of meters to kilometers

- Mean free path??

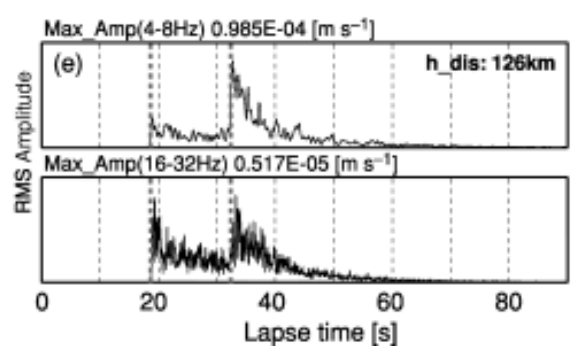

Crustal Earthquakes in Japan 


\section{Inner Core Coda Waves}
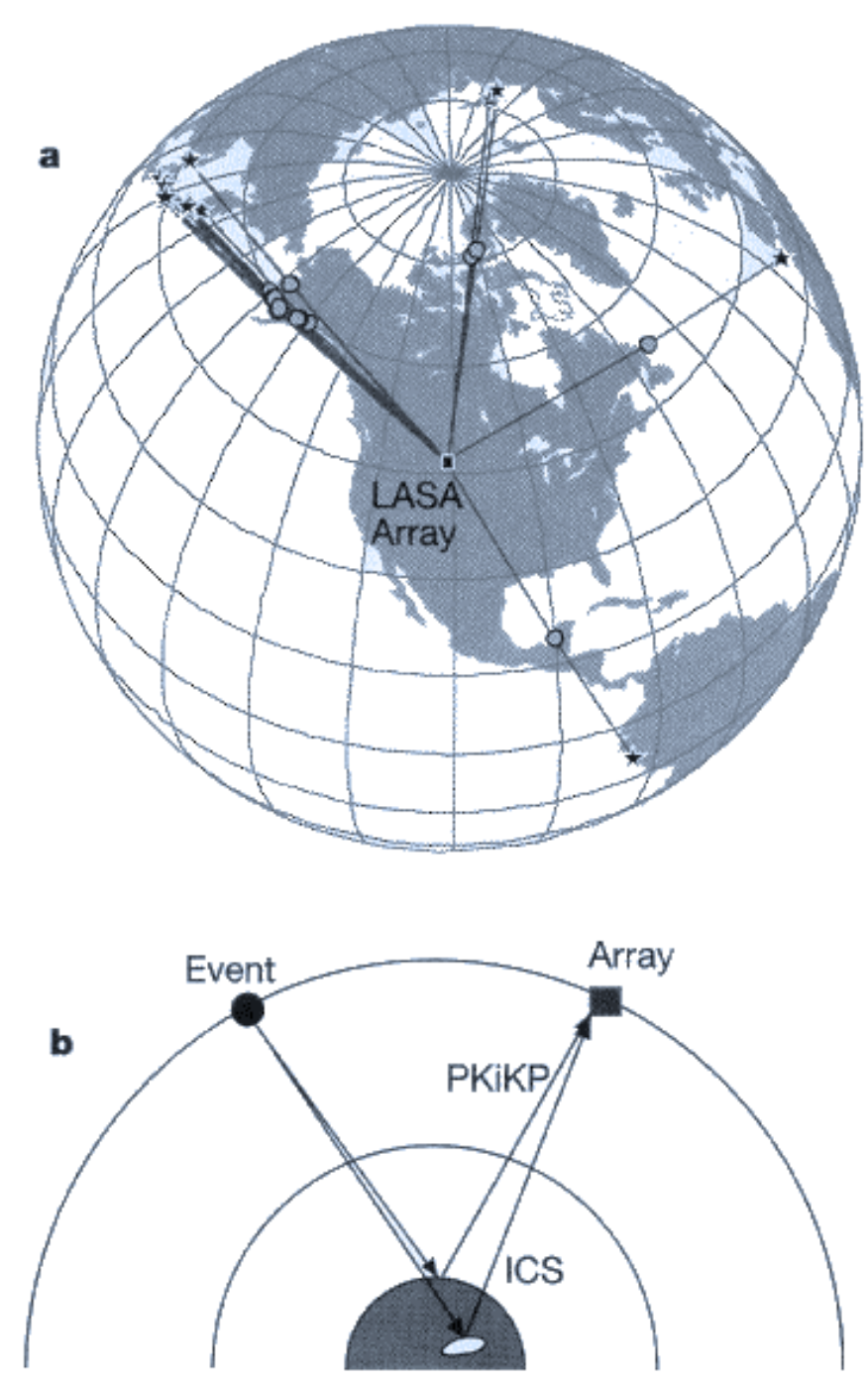

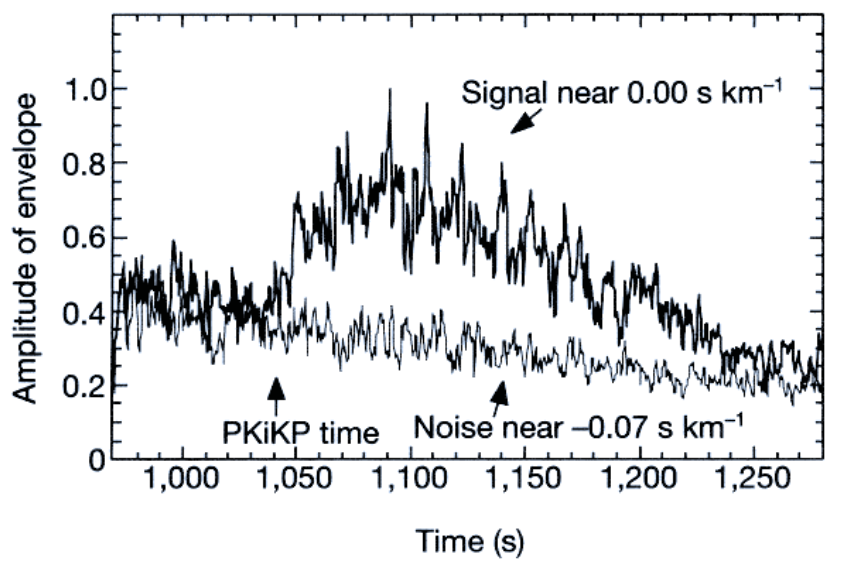

b

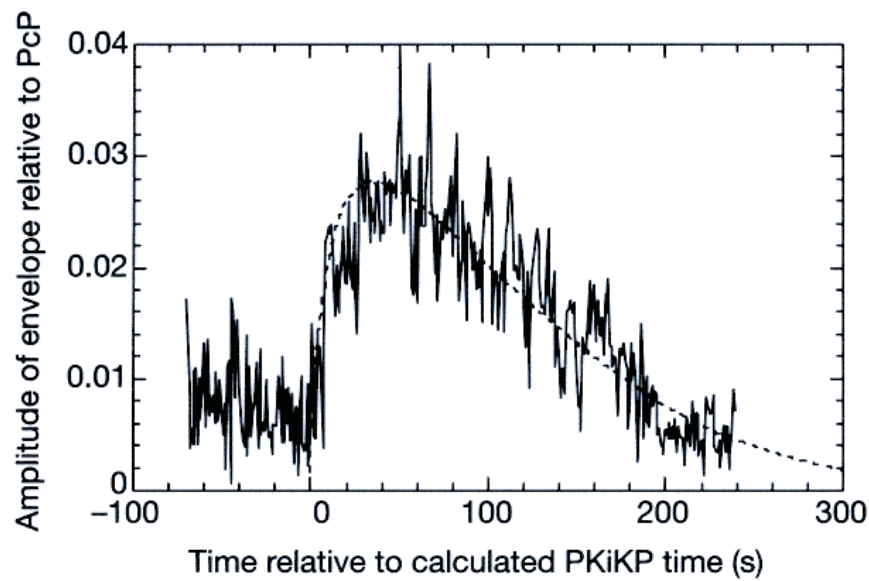

Vidale and Earle, Nature (2000) 


\section{Mesoscopic physics with seismic waves}

- Equipartition (Hennino et al., PRL, 2001)

- Weak localization (Larose et al., PRL, 2004)

- Green function retrieval from coda waves (Campillo and Paul, Science, 2003)

- Green function retrieval from noise (Aki, Bull. Earthquake Res. Institute, 1956 ; Shapiro and Campillo, GRL, 2004)

Tomography

Monitoring

- Coda wave interferometry (Diffusing Acoustic Wave Spectroscopy) (Poupinet et al., JGR, 1984; Sens-Schoenfelder and Wegler, GJI, 2006; Brenguier et al., Nature Geoscience 2007) 


\section{Content}

\section{(1) Observation of seismic coda waves}

(2) Equipartition of seismic waves

(3) Green function reconstruction

(4) Monitoring the Earth with coda waves

(5) Weak localization of seismic waves

(6) Phase statistics of coda waves 


\section{Pynion Flats Observatory Array}

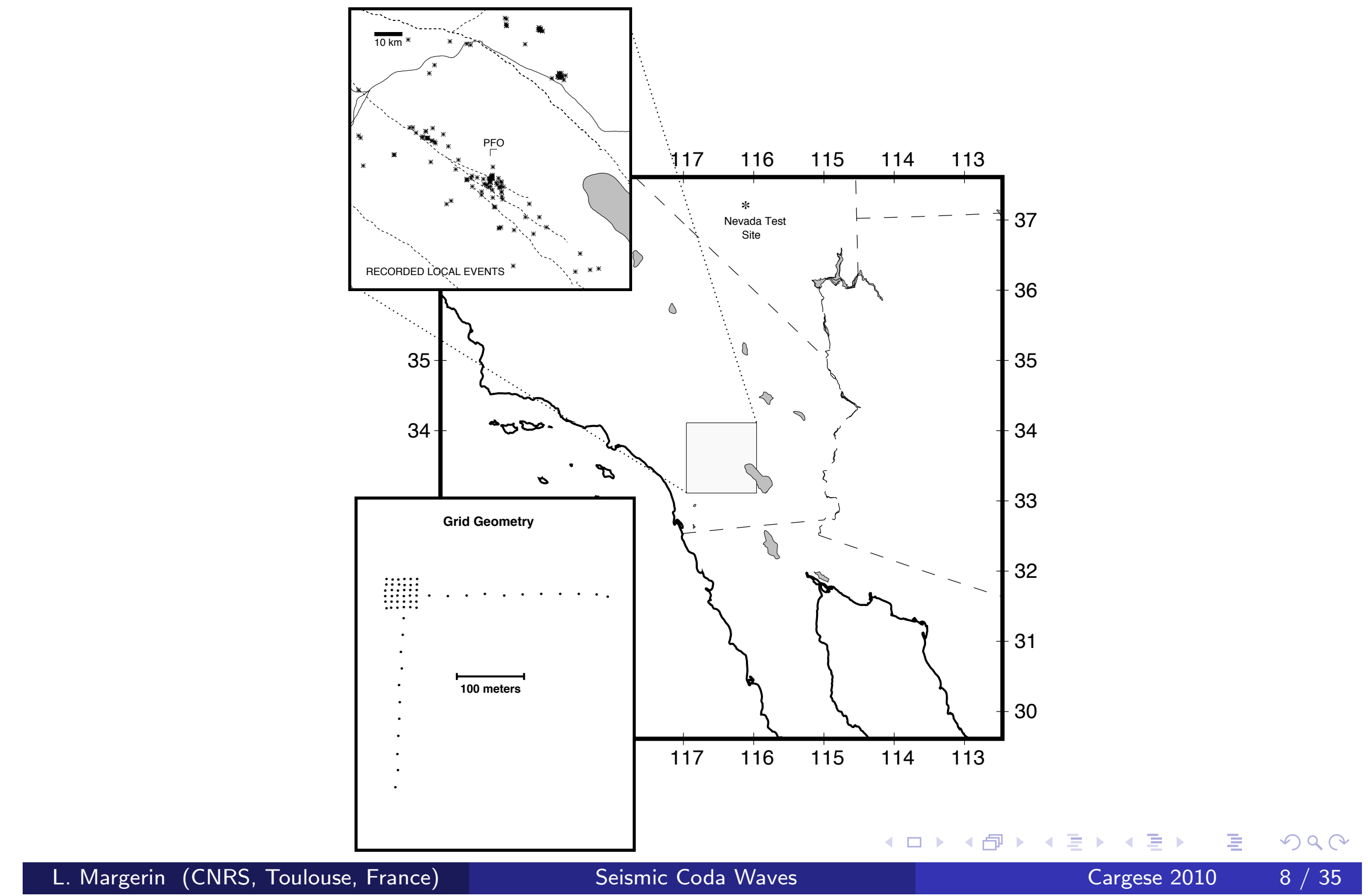




\section{Data from California}

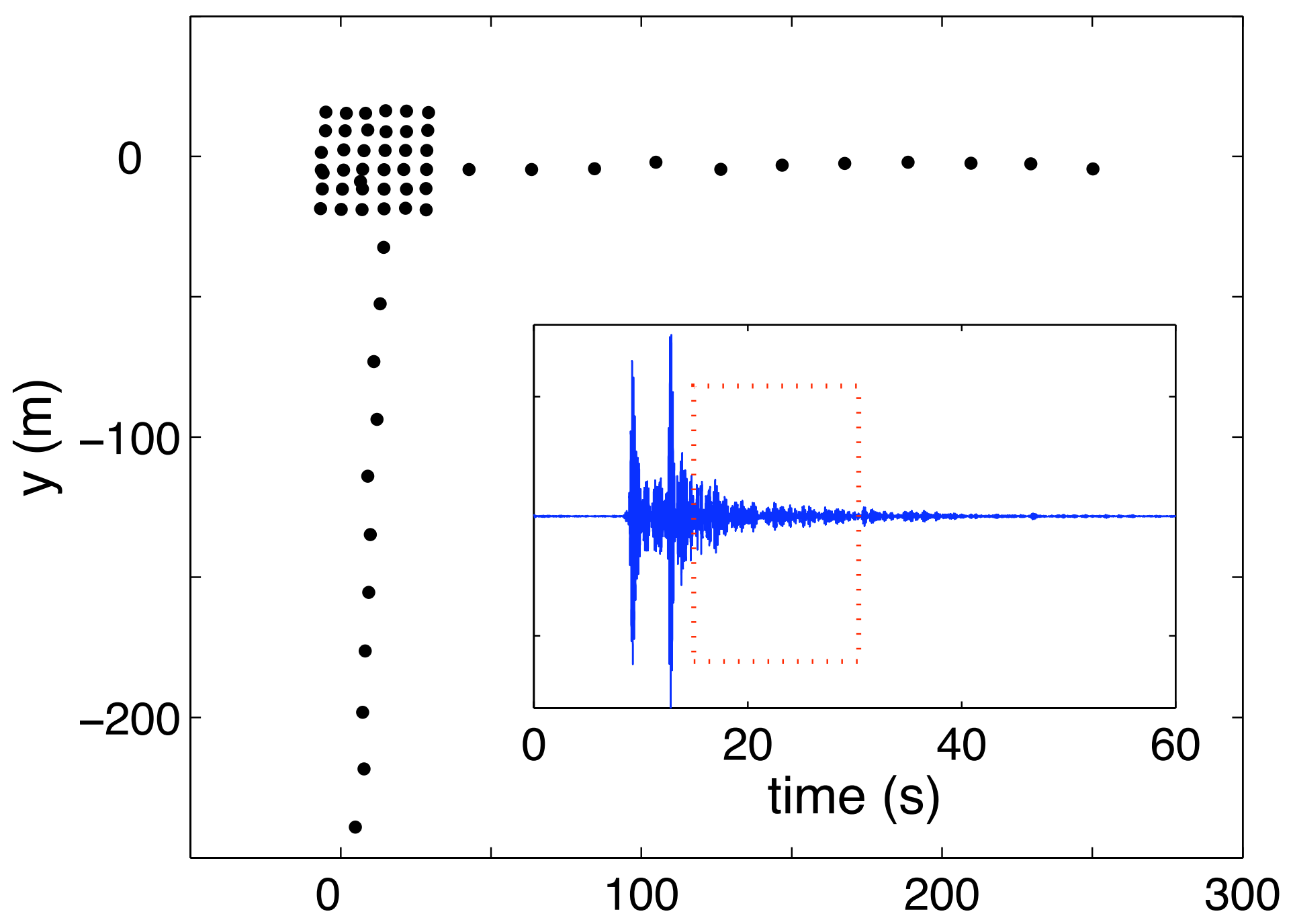




\section{Array Analysis}
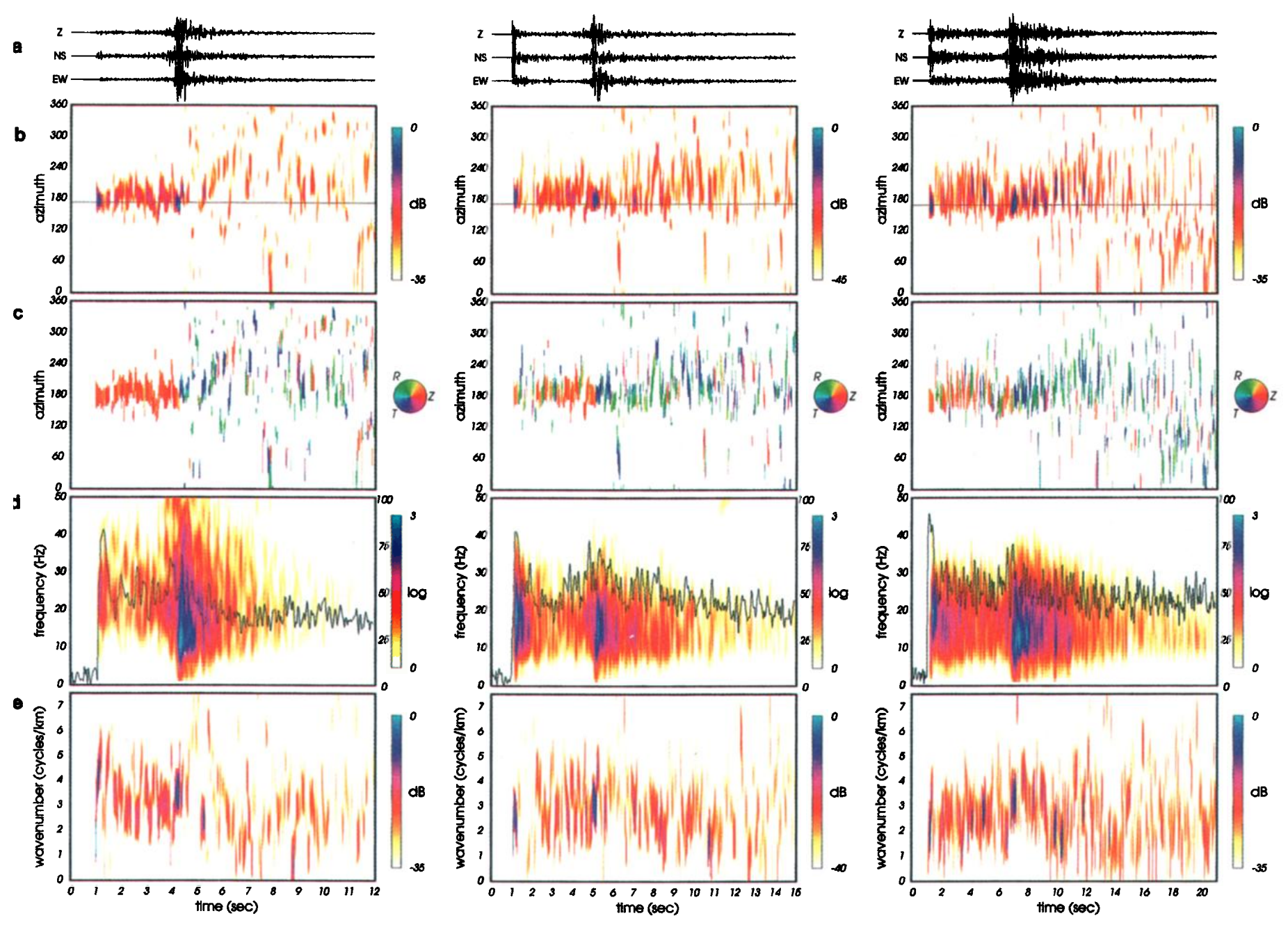

Wagner, JGR, 103, 1998 


\section{Stablization of Vertical to Horizontal Kinetic Energy Ratio}
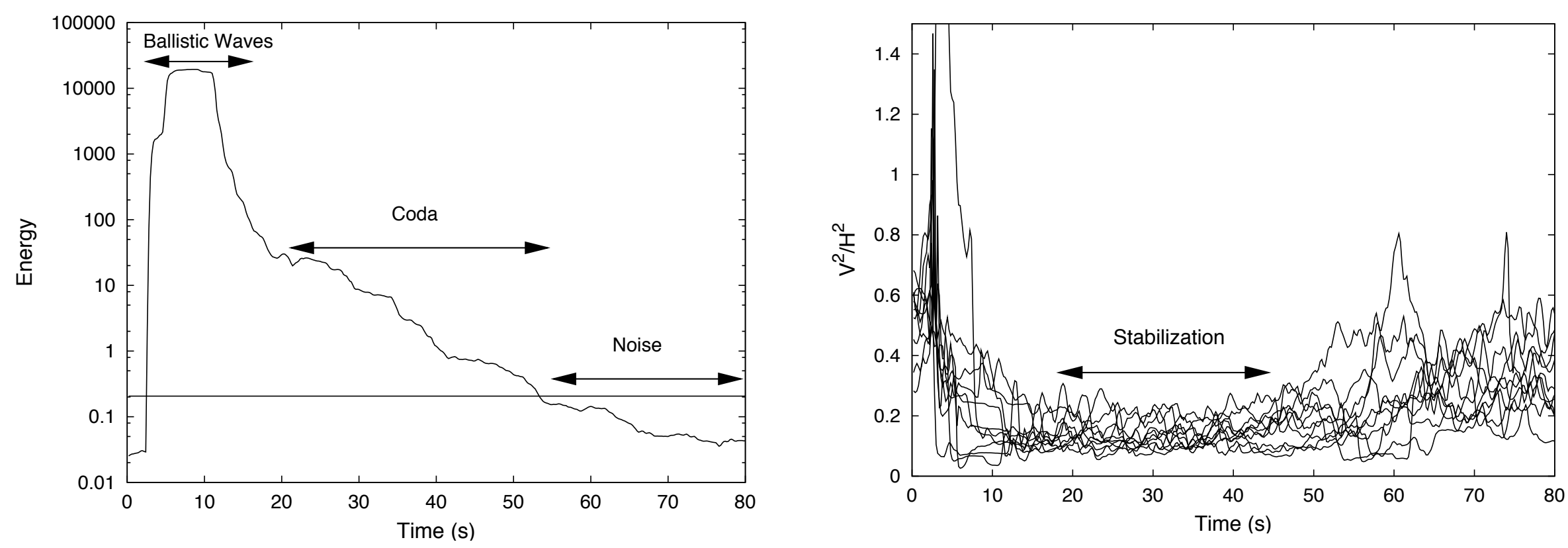

$$
\begin{aligned}
& V^{2}=\int_{t-T}^{t+T} \rho \omega^{2} u_{z}^{2}(\omega, \tau) d \tau \\
& H^{2}=\int_{t-T}^{t+T} \rho \omega^{2}\left(u_{x}^{2}(\omega, \tau)+u_{y}^{2}(\omega, \tau)\right) d \tau
\end{aligned}
$$




\section{Frequency-dependent $V^{2} / H^{2}$ partition ratio}

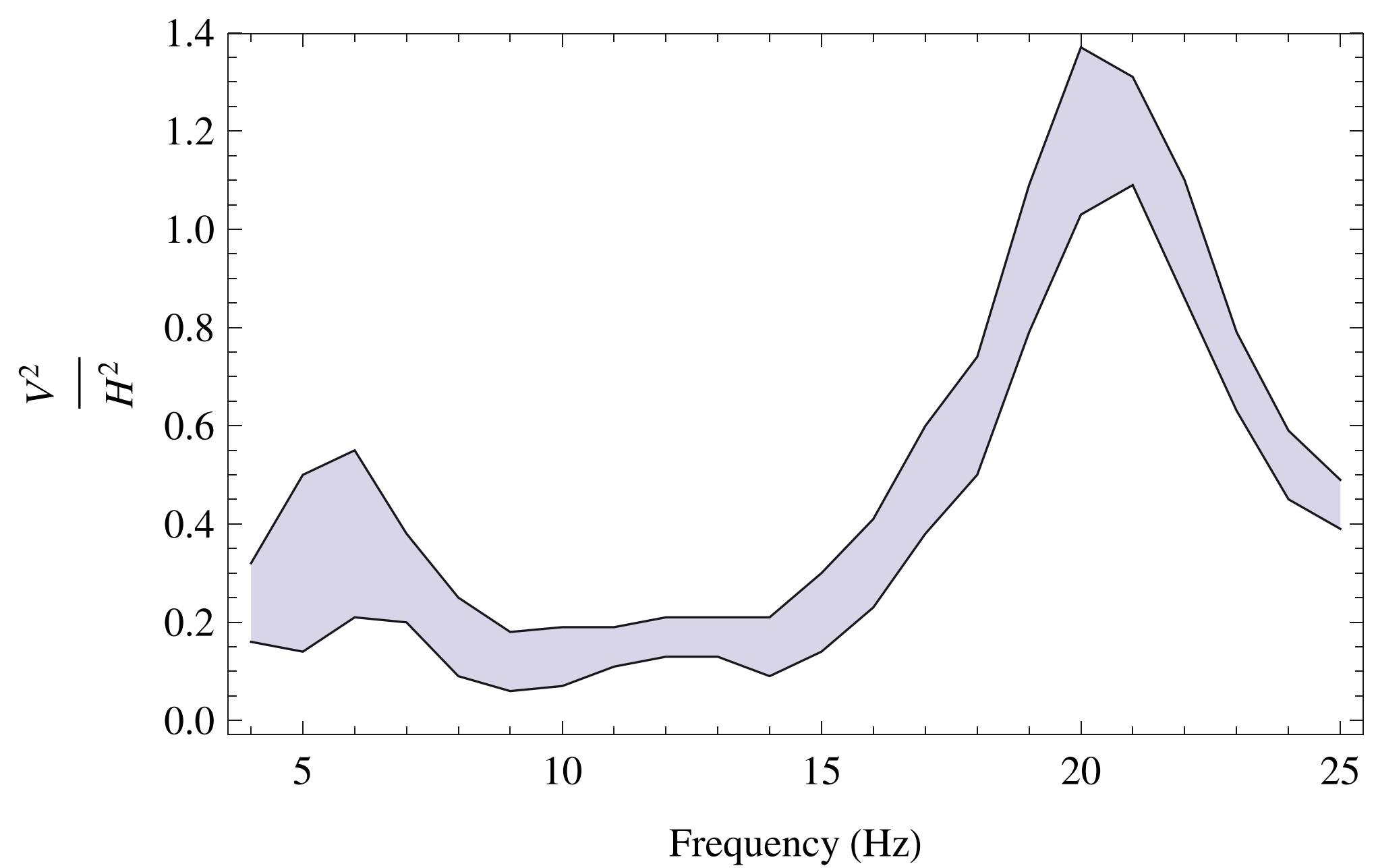




\section{Equipartition}

"In a small frequency band, all the modes are excited to equal energy" (Weaver, 1982)

"Reference" Earth = Layered Half-Space

$\frac{v_{\text {vs1,d1,vp1,h1 }}}{\text { vsi,di,vpi,hi }}$
$\frac{\mathbf{u} \text { Half-Space }}{(t, \boldsymbol{r})=\sum_{n} a_{n} \phi_{n}(\boldsymbol{r}) e^{-i \omega_{n} t}}$

"True" Earth = Disordered Half-Space

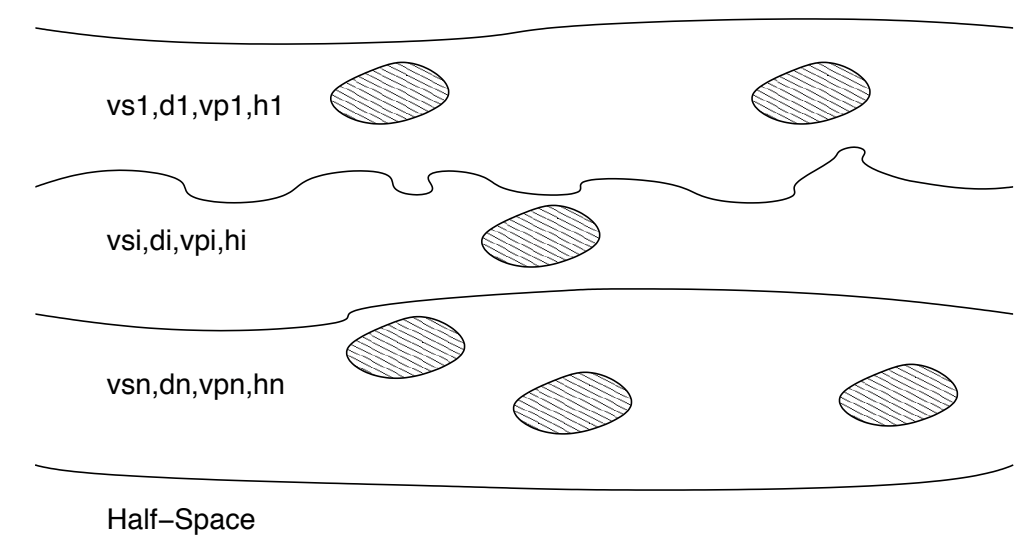

$\mathbf{u}(t, \mathbf{r})=\sum_{n} a_{n}(t) \phi_{n}(\mathbf{r}) e^{-i \omega_{n} t}$

$$
\begin{gathered}
\text { Assumption: }\left\langle a_{n}(t) a_{n^{\prime}}^{*}(t)\right\rangle=\sigma^{2}(t) \delta_{n n^{\prime}} \\
\text { Consequence: }\left\langle u_{i}\left(\mathbf{x}_{A}, \omega\right) u_{j}\left(\mathbf{x}_{B}, \omega\right)^{*}\right\rangle \approx C \operatorname{Im} G_{i j}\left(\mathbf{x}_{A}, \mathbf{x}_{B}, \omega\right)
\end{gathered}
$$




\section{Theory vs Observations}

\begin{tabular}{|c|}
\hline Velocity Model \\
\hline$h_{1}=4 \mathrm{~m}$ \\
$\alpha_{1}=300 \mathrm{~m} / \mathrm{s}$ \\
$\beta_{1}=150 \mathrm{~m} / \mathrm{s}$ \\
$\rho_{1}=2200 \mathrm{~kg} / \mathrm{m}^{3}$ \\
\hline$h_{2}=11 \mathrm{~m}$ \\
$\alpha_{2}=900 \mathrm{~m} / \mathrm{s}$ \\
$\beta_{2}=500 \mathrm{~m} / \mathrm{s}$ \\
$\rho_{2}=2200 \mathrm{~kg} / \mathrm{m}^{3}$ \\
\hline$h_{3}=50 \mathrm{~m}$ \\
$\alpha_{3}=3100 \mathrm{~m} / \mathrm{s}$ \\
$\beta_{3}=1600 \mathrm{~m} / \mathrm{s}$ \\
$\rho_{3}=2700 \mathrm{~kg} / \mathrm{m}^{3}$ \\
\hline$\alpha_{\infty}=5400 \mathrm{~m} / \mathrm{s}$ \\
$\beta_{\infty}=3000 \mathrm{~m} / \mathrm{s}$ \\
$\rho_{\infty}=2700 \mathrm{~kg} / \mathrm{m}^{3}$ \\
\hline
\end{tabular}
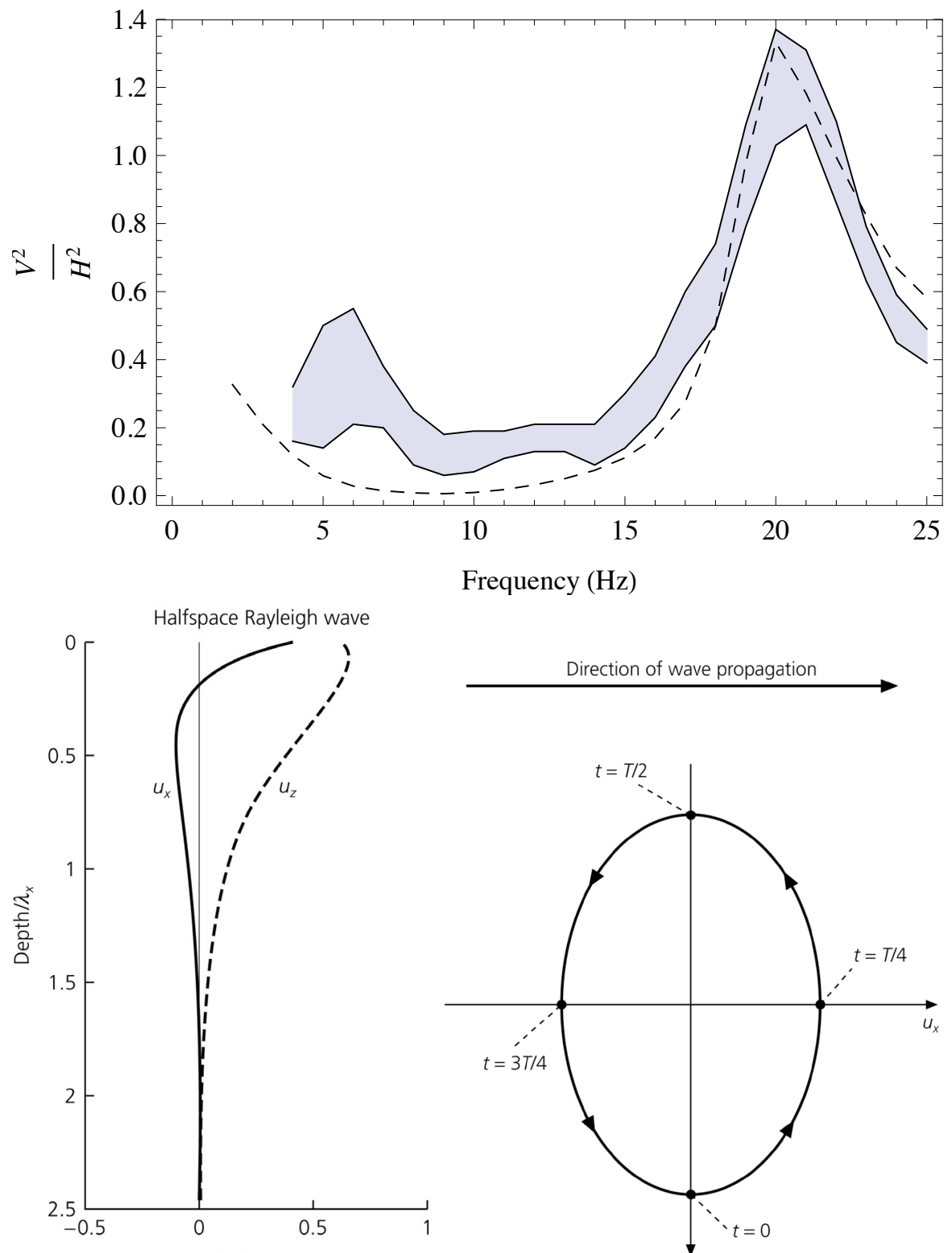


\section{Content}

\section{(1) Observation of seismic coda waves}

(2) Equipartition of seismic waves

(3) Green function reconstruction

(4) Monitoring the Earth with coda waves

(5) Weak localization of seismic waves

(6) Phase statistics of coda waves 


\section{Experimental Set-Up}

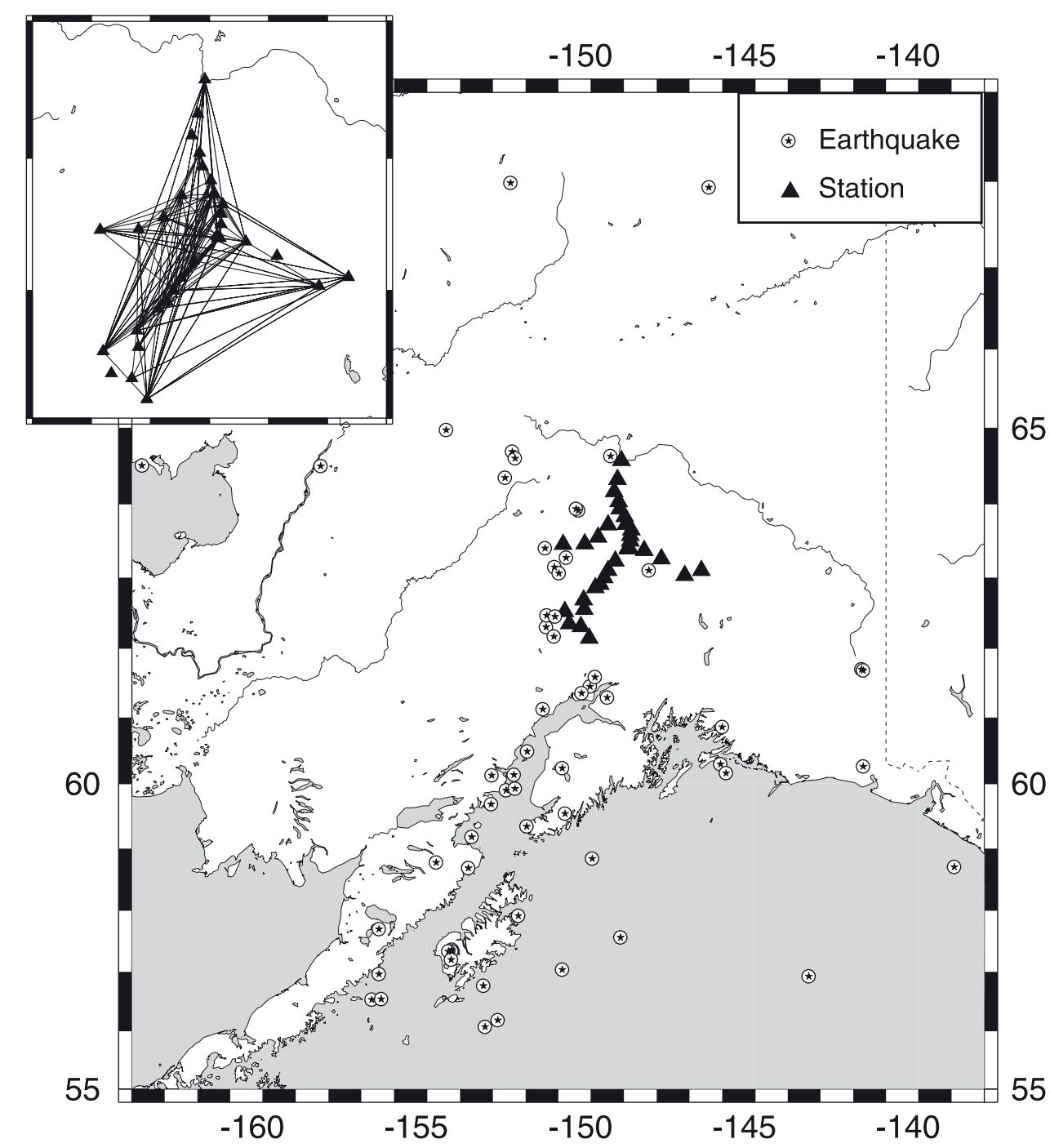




\section{Cross-correlation of coda waves}
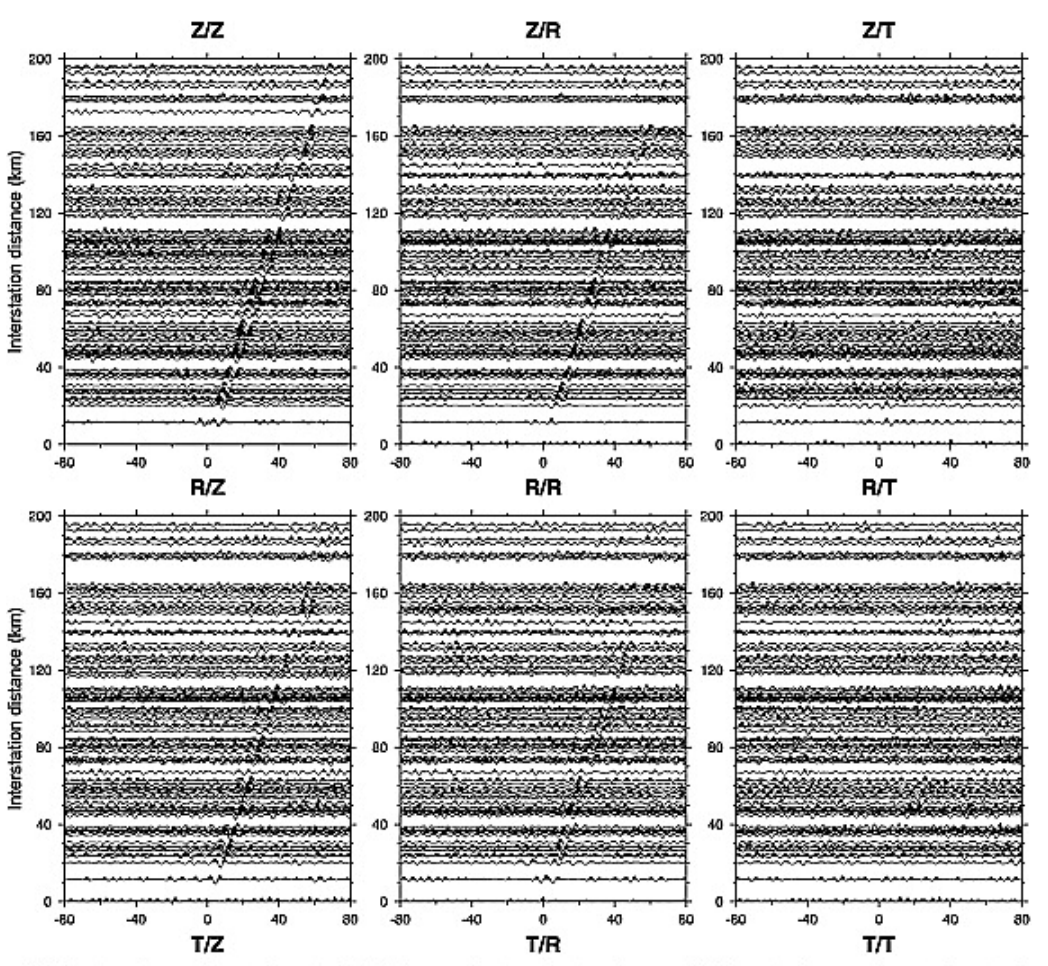

- $C_{i j}\left(\mathbf{x}_{a}, \mathbf{x}_{b}, \tau\right)=$ $\int u_{i}\left(\mathbf{x}_{a}, t-\tau / 2\right) u_{j}\left(\mathbf{x}_{b}, t+\tau / 2\right) d t$

- Source average

- Reconstruction of Rayleigh and Love waves fundamental mode

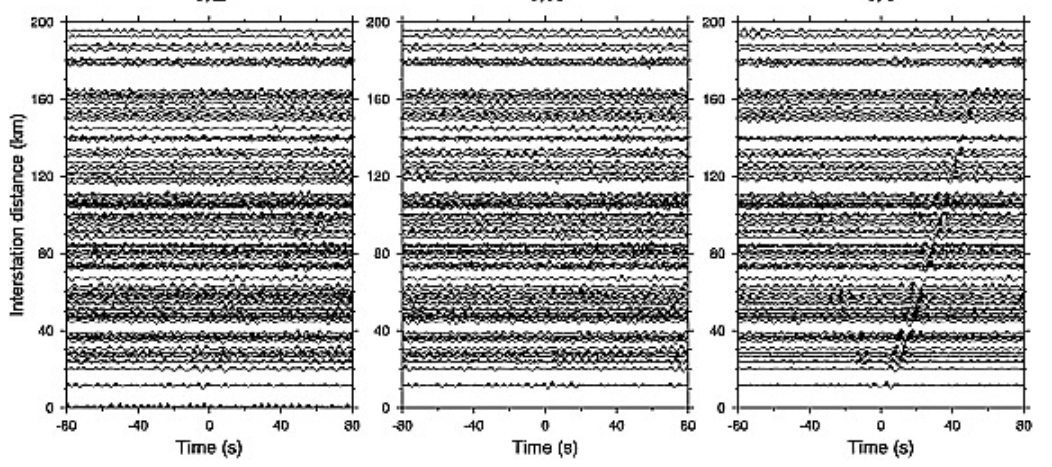

- Temporal asymmetry 


\section{Understanding the temporal asymmetry}

Results from 2-D F.D. simulation

Early coda
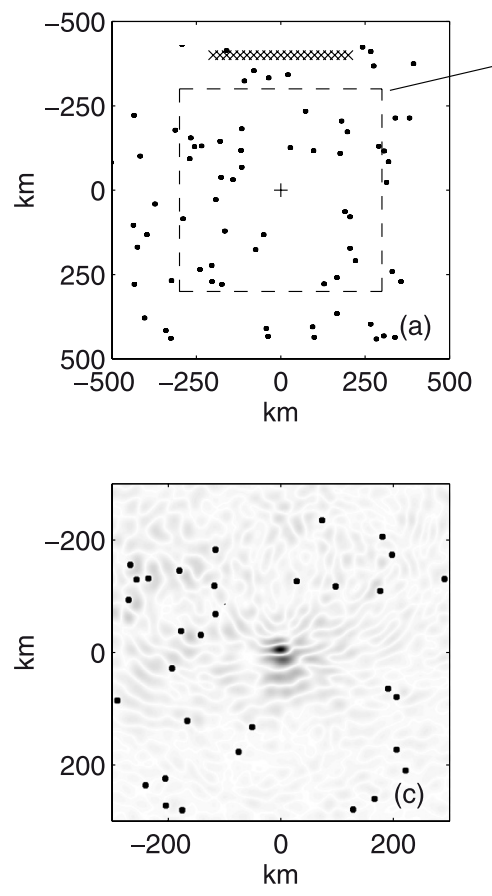

$$
\frac{d\langle u(\mathbf{R}-\mathbf{r} / 2, t-\tau / 2) u(\mathbf{R}+\mathbf{r} / 2, t+\tau / 2)\rangle}{d \tau} \propto
$$$$
E(\mathbf{R}, t)[G(\mathbf{r}, \tau)-G(\mathbf{r},-\tau)]-3 J(\mathbf{R}, t) \cdot \nabla_{\mathbf{r}}[G(\mathbf{r}, \tau)-G(\mathbf{r},-\tau)]
$$

Late coda
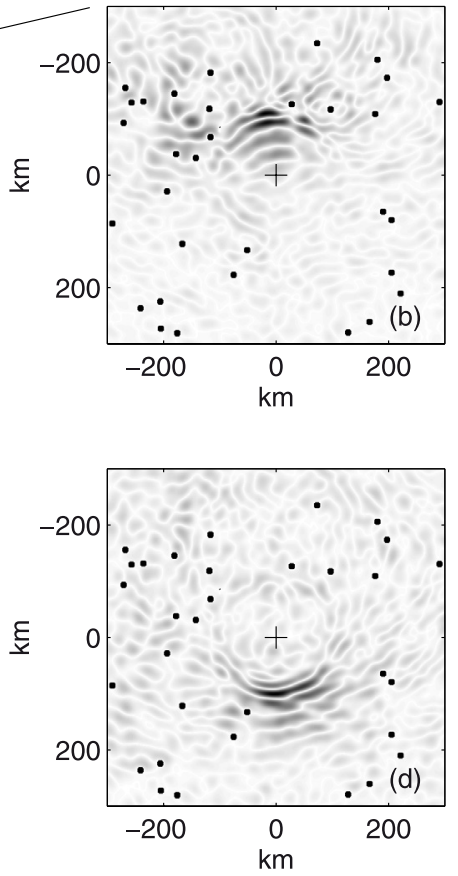

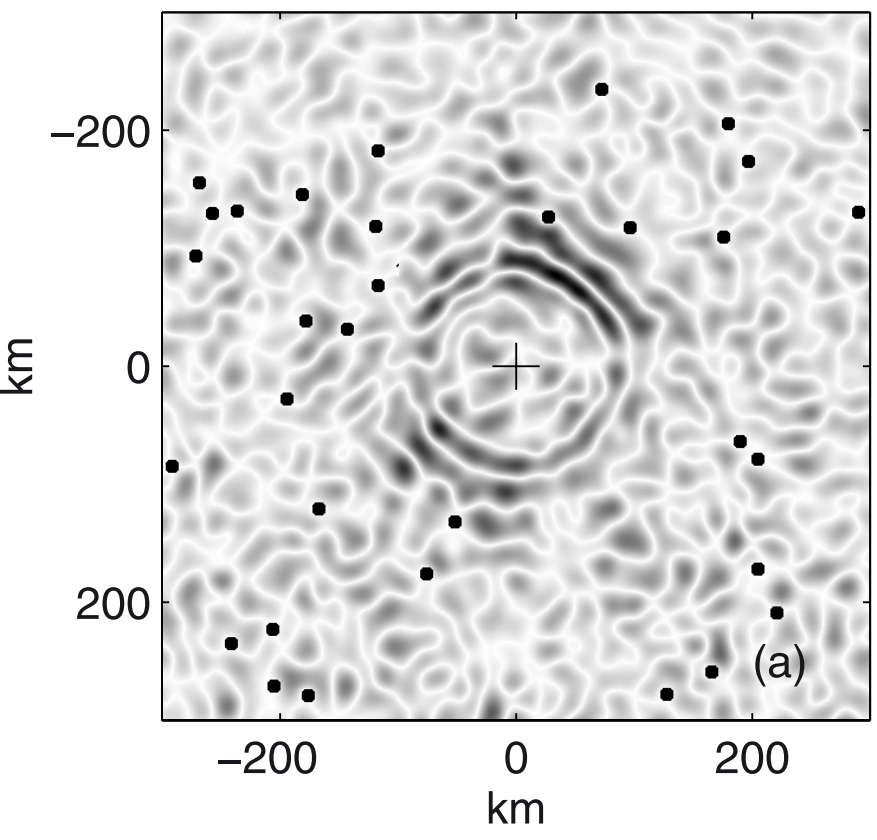

(B.V.T., PRL, 2003) 


\section{GF reconstruction with the coda of noise based GF}

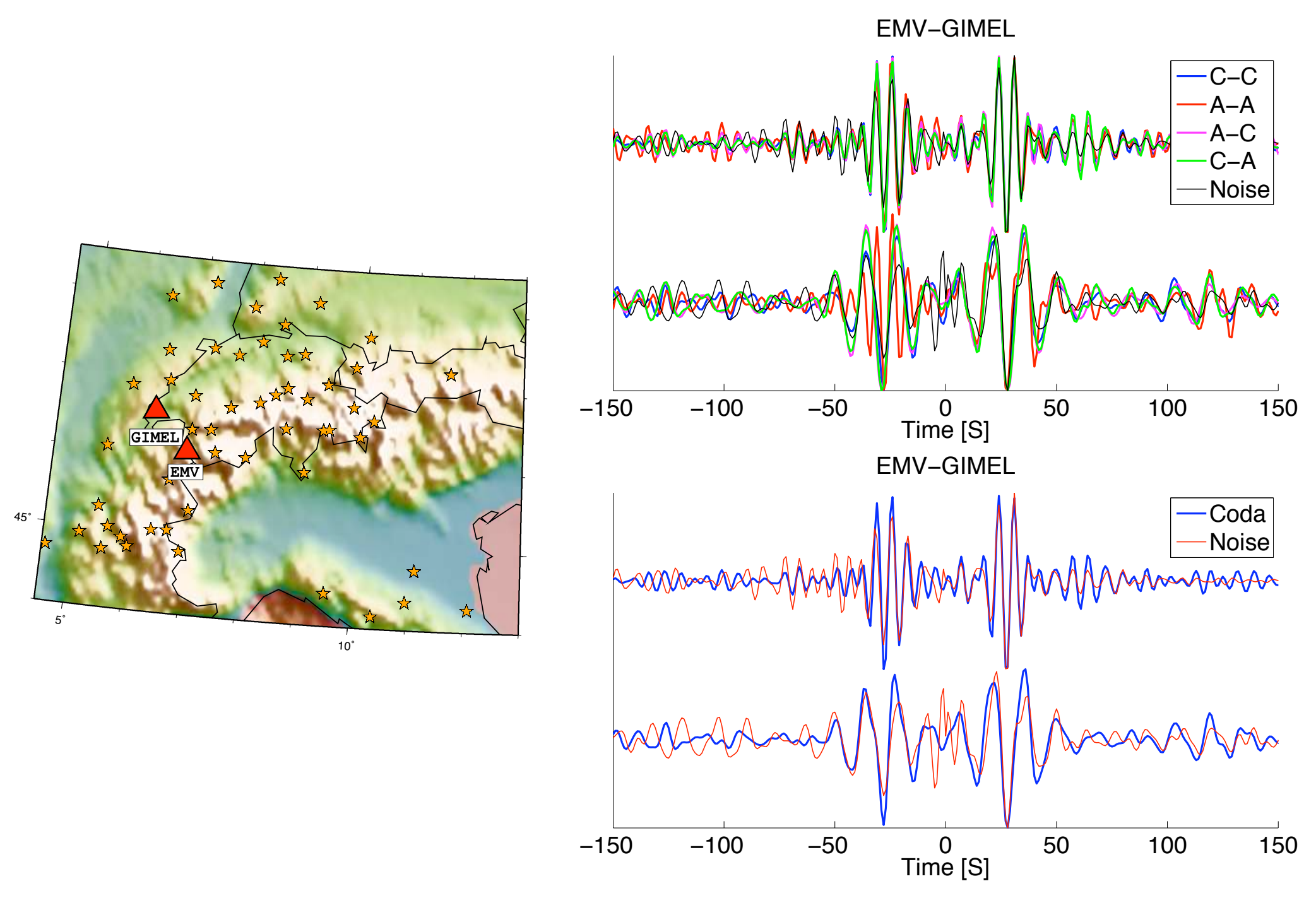




\section{Content}

\section{(1) Observation of seismic coda waves}

(2) Equipartition of seismic waves

(3) Green function reconstruction

(4) Monitoring the Earth with coda waves

(5) Weak localization of seismic waves

(6) Phase statistics of coda waves 


\section{Earthquake doublets}

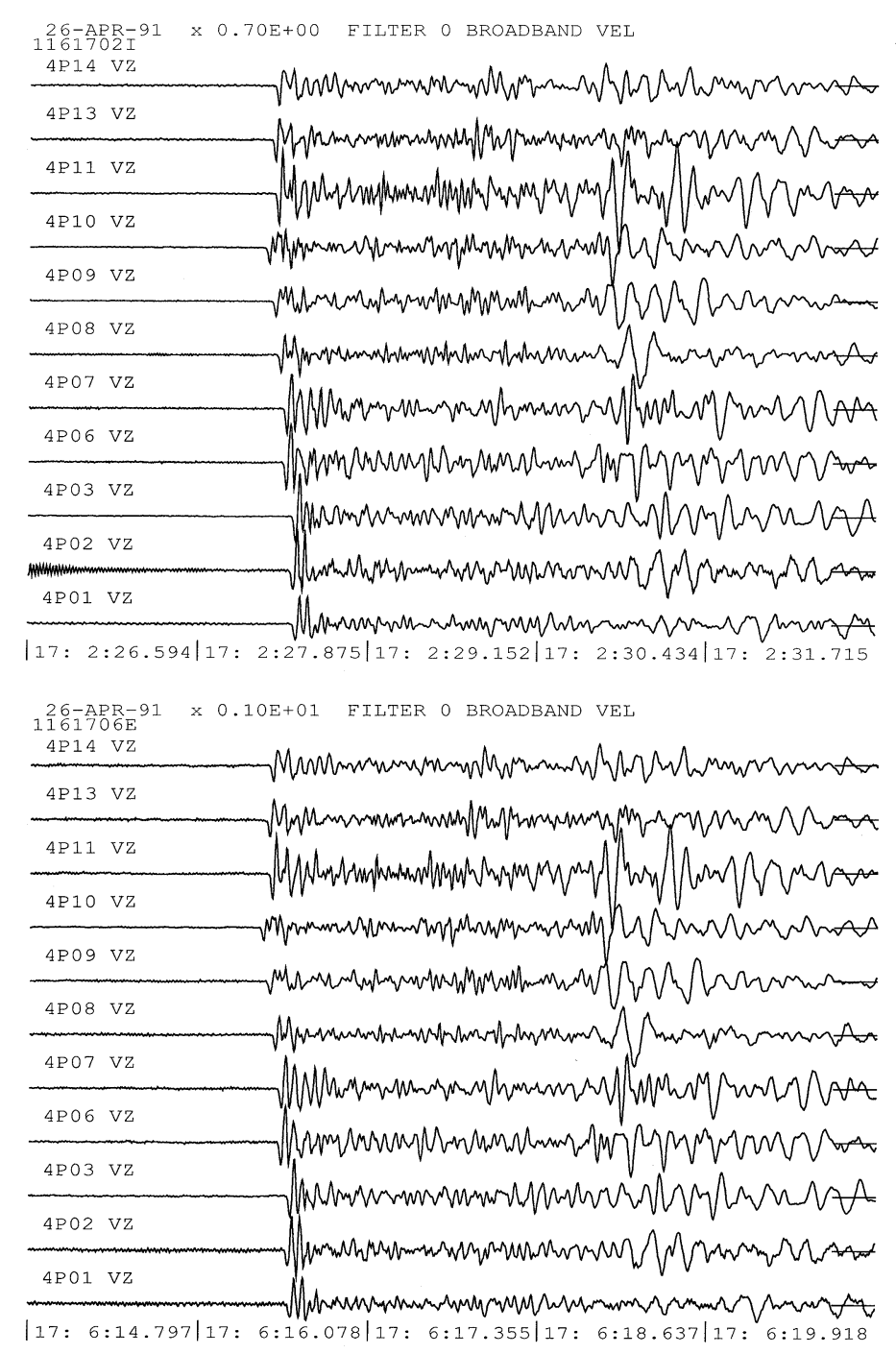

- Same location

- Same mechanism

- Nearly identical waveforms

- Drawback: no continuous monitoring 


\section{Repeated shots recorded on Merapi Volcano}

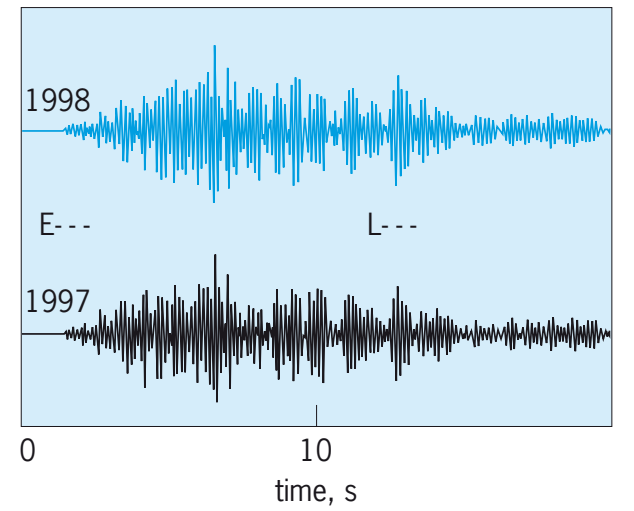

(a)

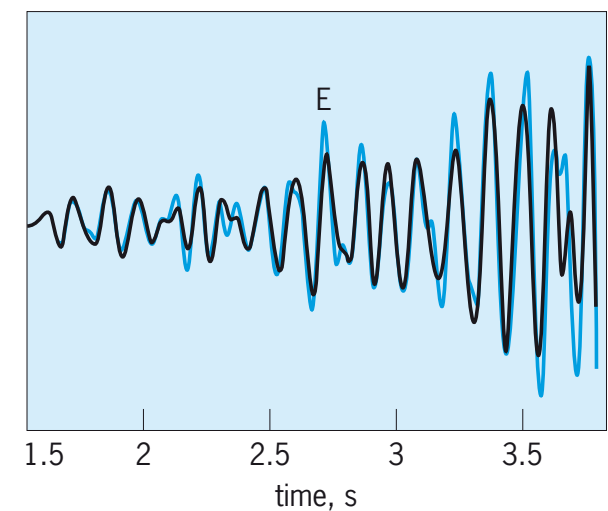

(b)

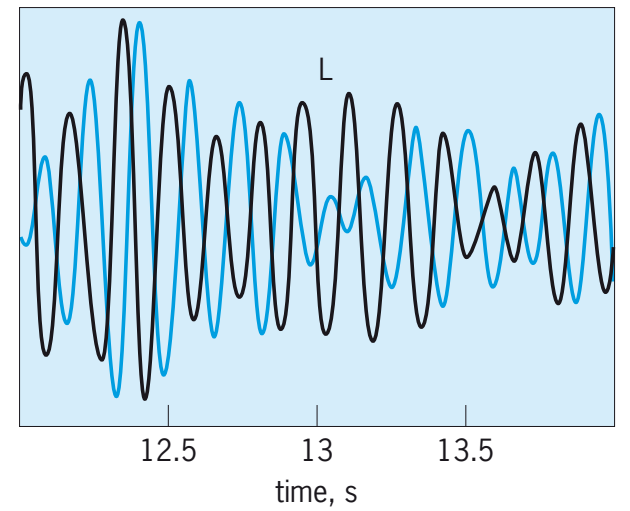

(c)

- No changes on the first arrival

- Increasing delay time in the coda

Stretching of the signal $\approx$ tiny velocity change in the medium

- Active source experiments are expensive 


\section{Monitoring with seismic noise}

\section{Example on Piton de la Fournaise}

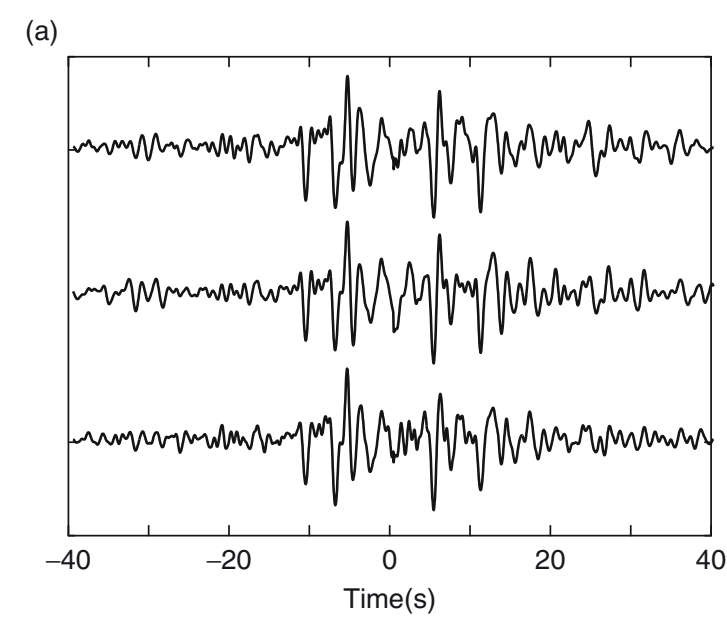

- Green function obtained from cross-correlation of seismic noise

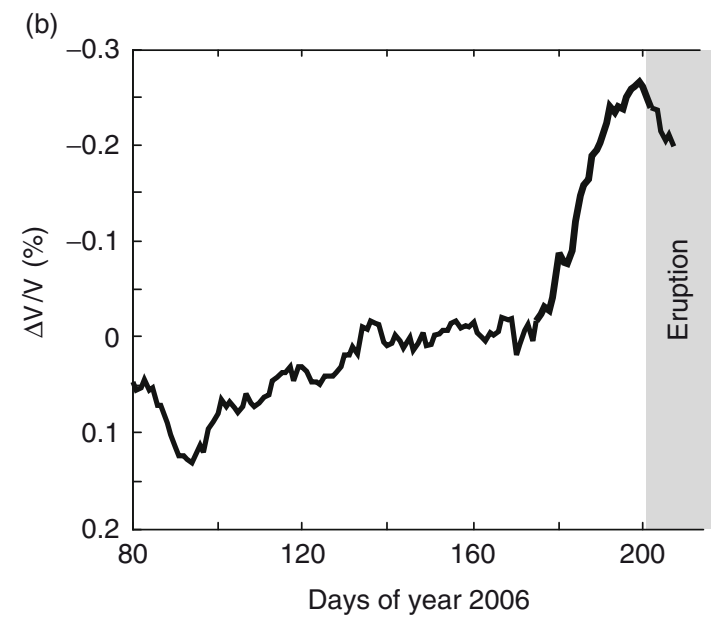

- Measurement of stretching parameter in the coda

"Passive image interferometry" (Sens-Schoenfelder and Wegler, GJI, 2006; Brenguier et al., Nature Geoscience, 2008; Brenguier et al., Science, 2008) 


\section{Content}

\section{(1) Observation of seismic coda waves}

(2) Equipartition of seismic waves

(3) Green function reconstruction

(4) Monitoring the Earth with coda waves

(5) Weak localization of seismic waves

(6) Phase statistics of coda waves 


\section{Specific issues in seismology}

Detection operates at the surface

Earthquakes sources are often at depth

Problem 1: Weak localization has size of a wavelength around the source Problem 2: The source mechanism
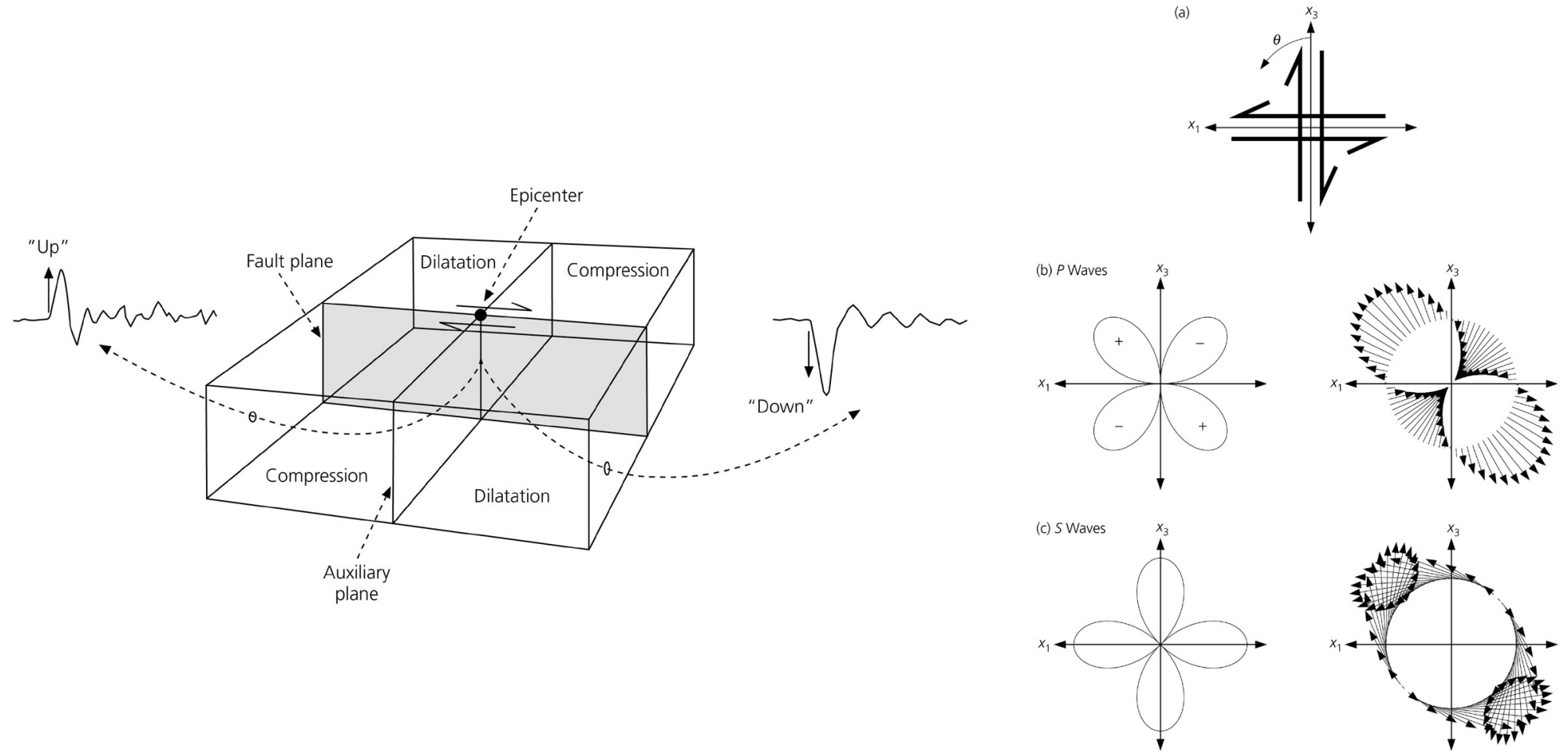


\section{Enhanced backscattering in a 2-D chaotic cavity}

Role of the source

Monopole

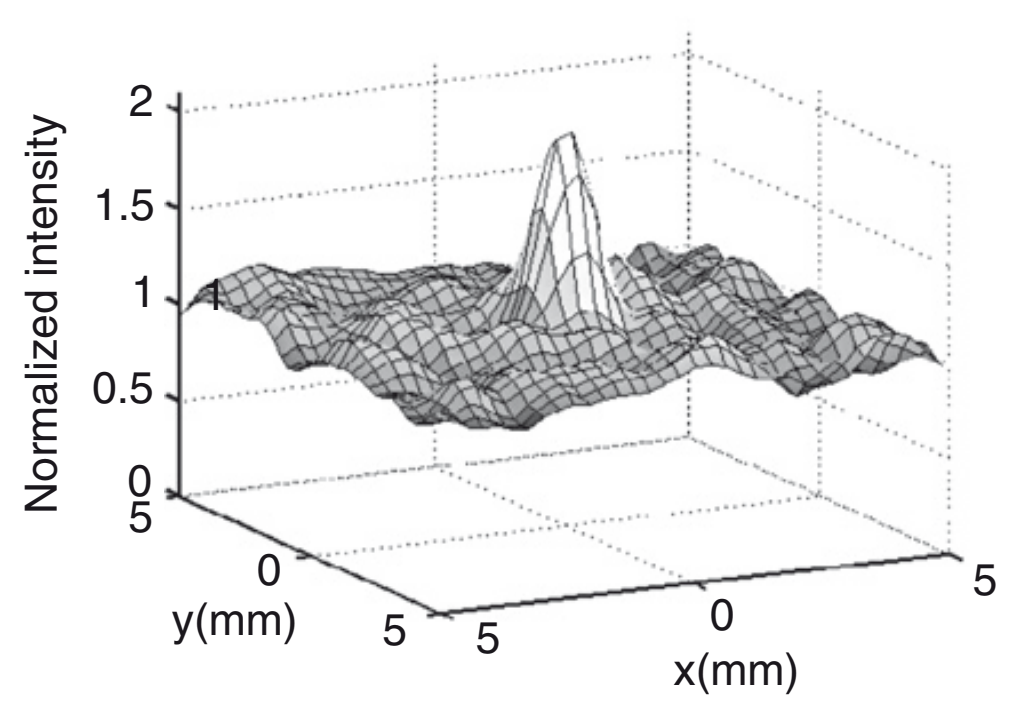

Dipole

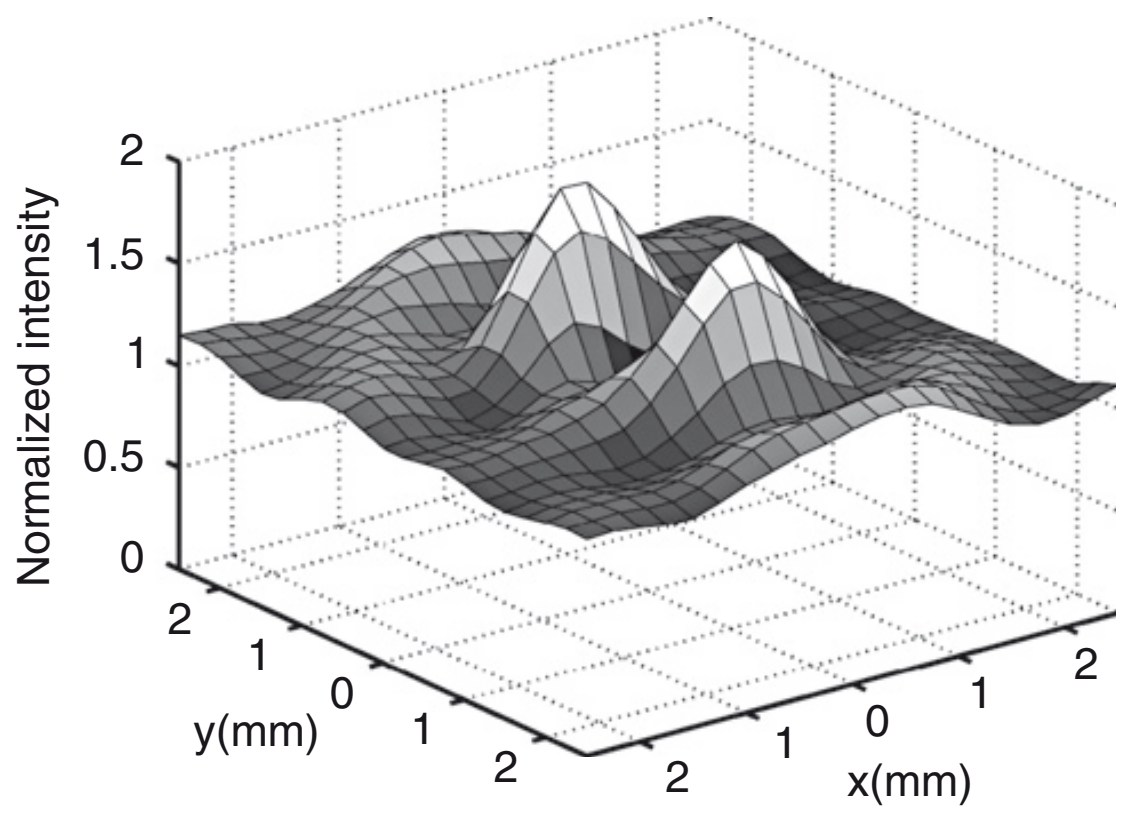

De Rosny et al., PRE, 2001 


\section{Small-scale seismic experiment}
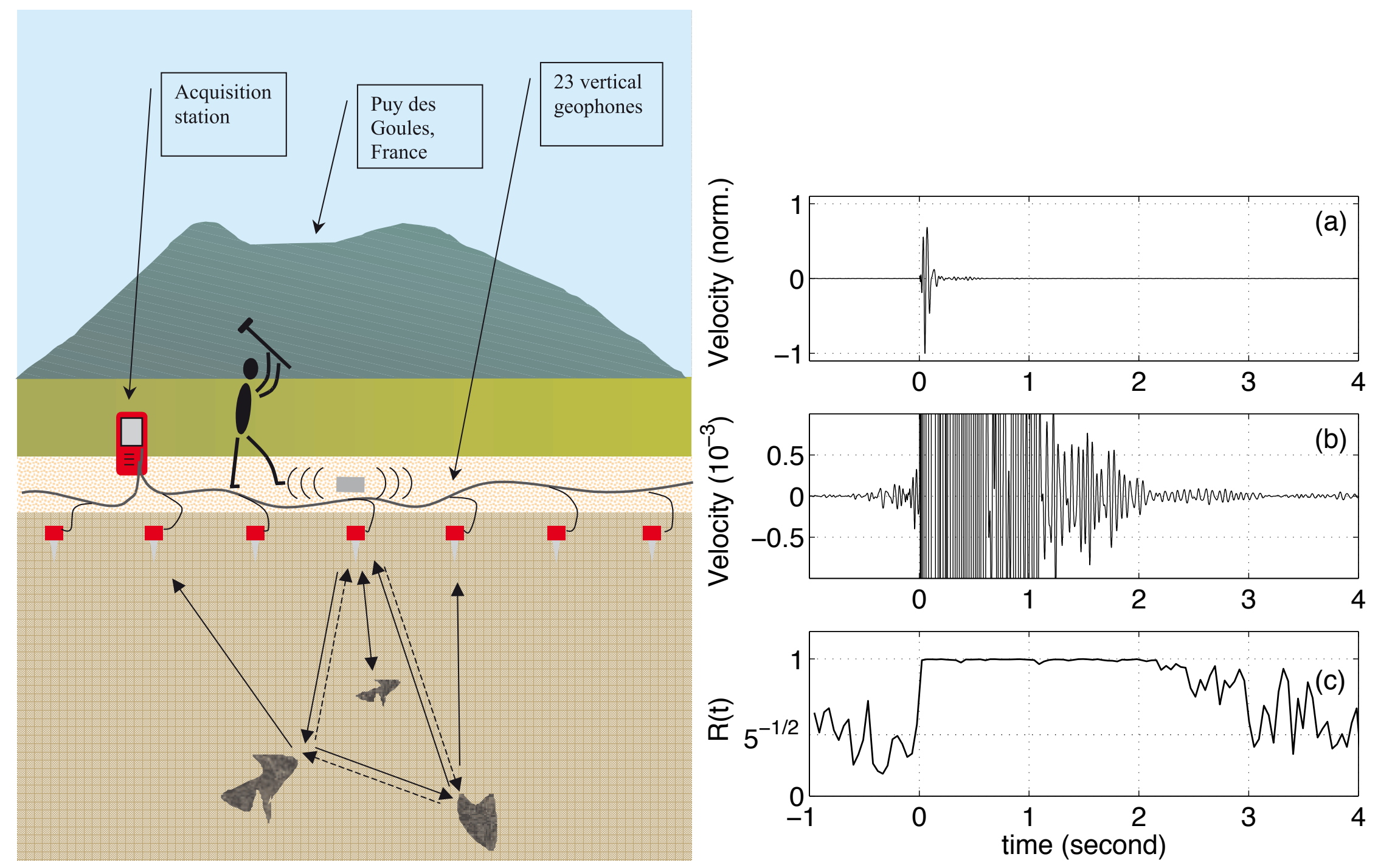


\section{Observation of weak localization}

Frequency dependence
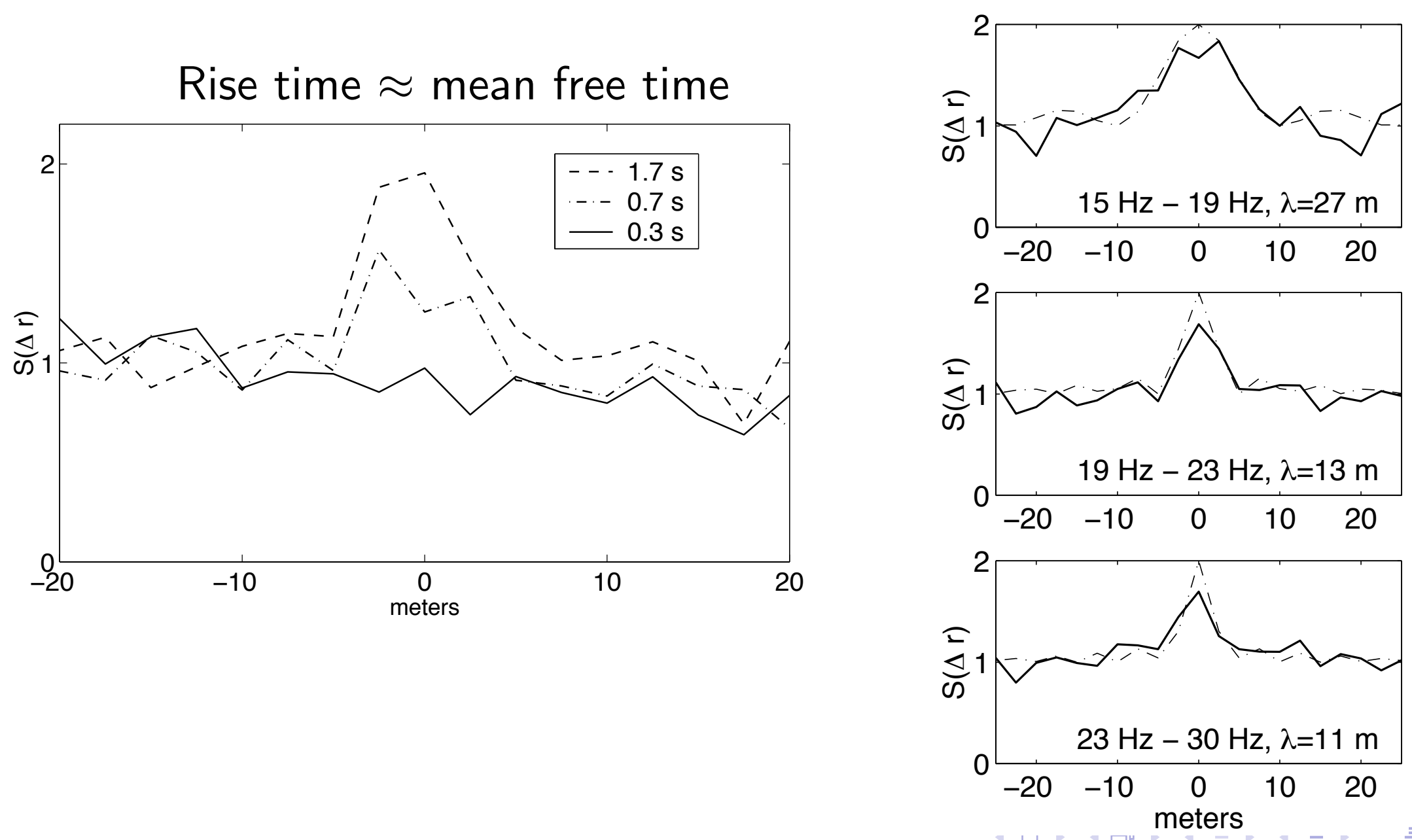


\section{Content}

\section{(1) Observation of seismic coda waves}

(2) Equipartition of seismic waves

(3) Green function reconstruction

(4) Monitoring the Earth with coda waves

(5) Weak localization of seismic waves

(6) Phase statistics of coda waves 


\section{Phase Statistics}

- Phase of the analytic signal

- Easy with seismic waves: spatial and temporal resolution

- Free from effect of absorption

- Simplifying assumptions :

Analyze the phase field of vertical components Wavefield obeys Circular Gaussian Statistics: 


\section{Data from California}

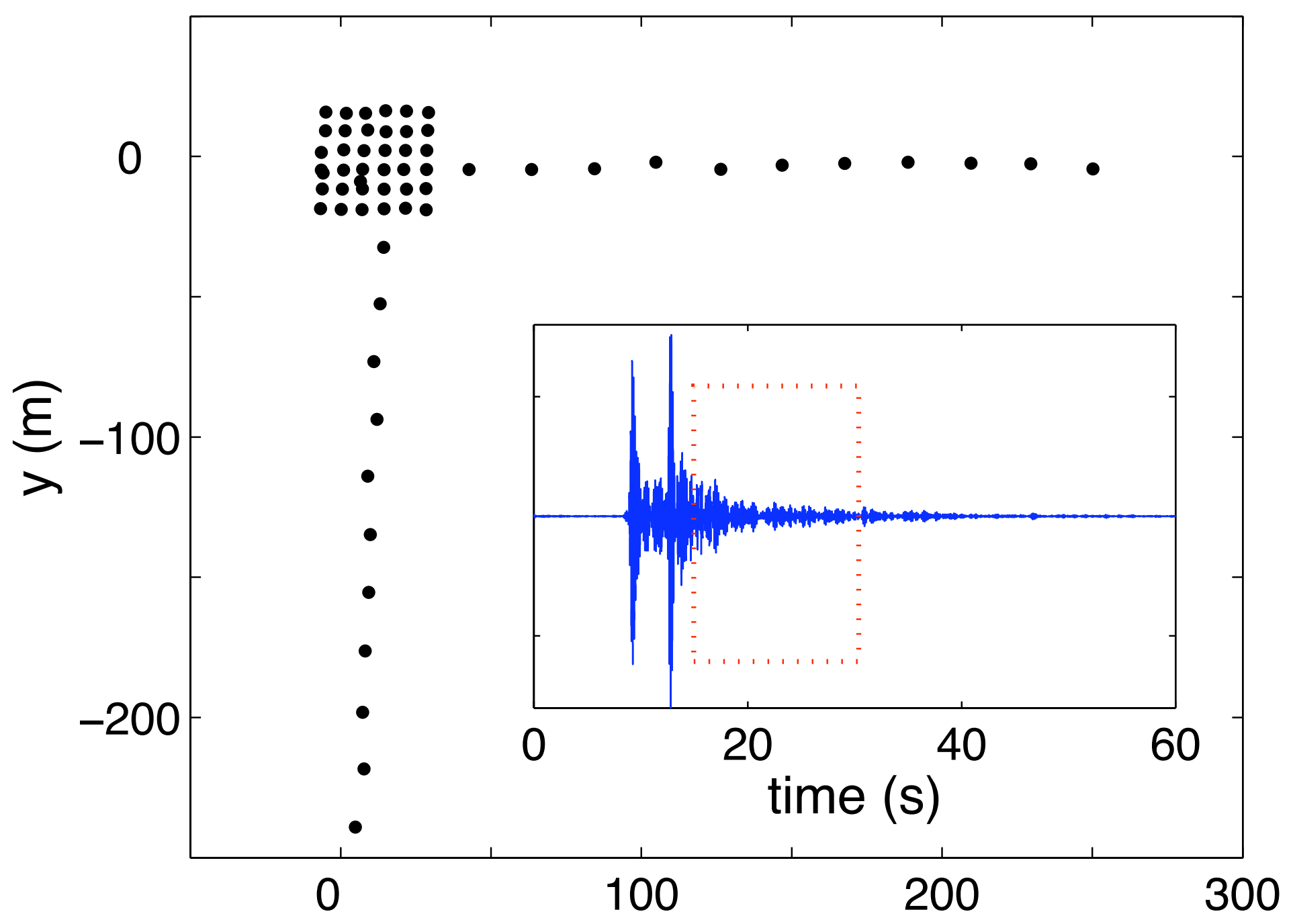




\section{Field and Intensity}

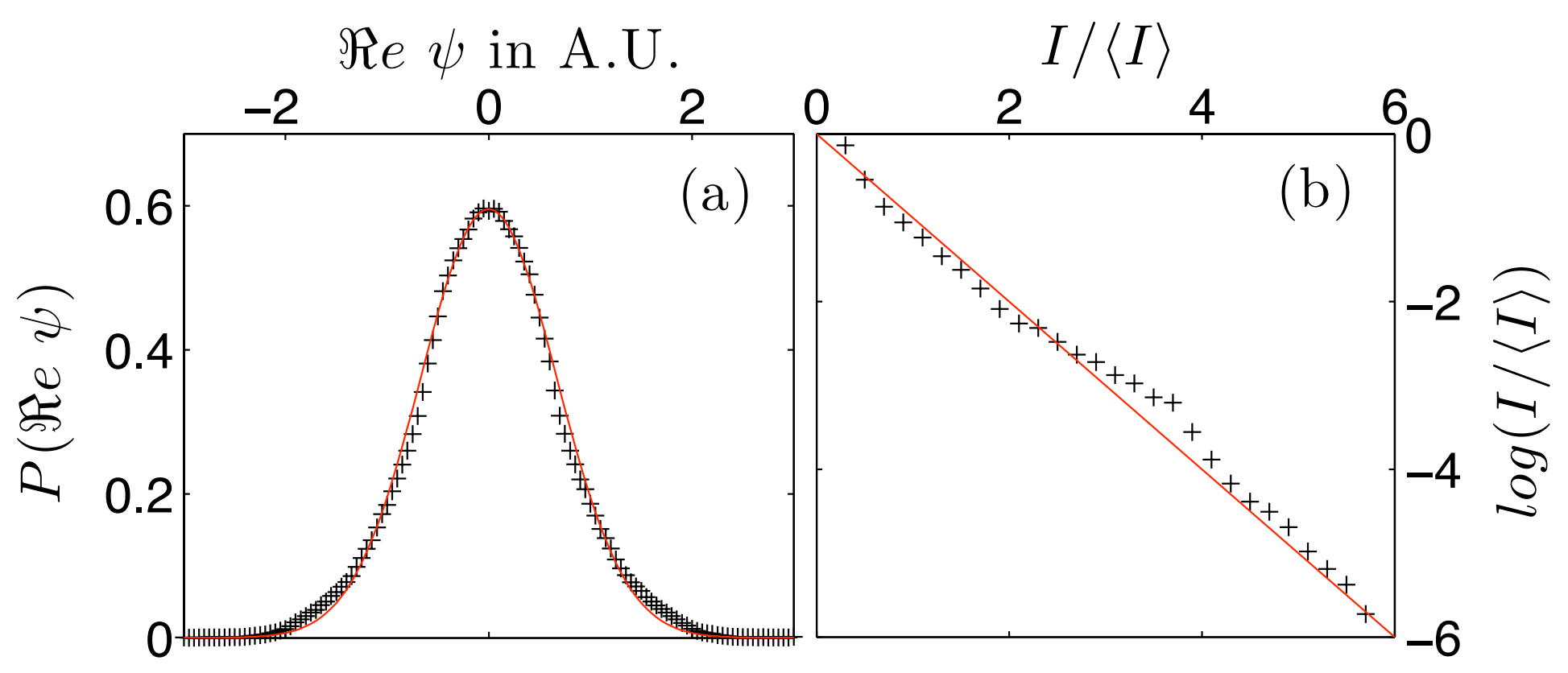




\section{2-Point Statistics}

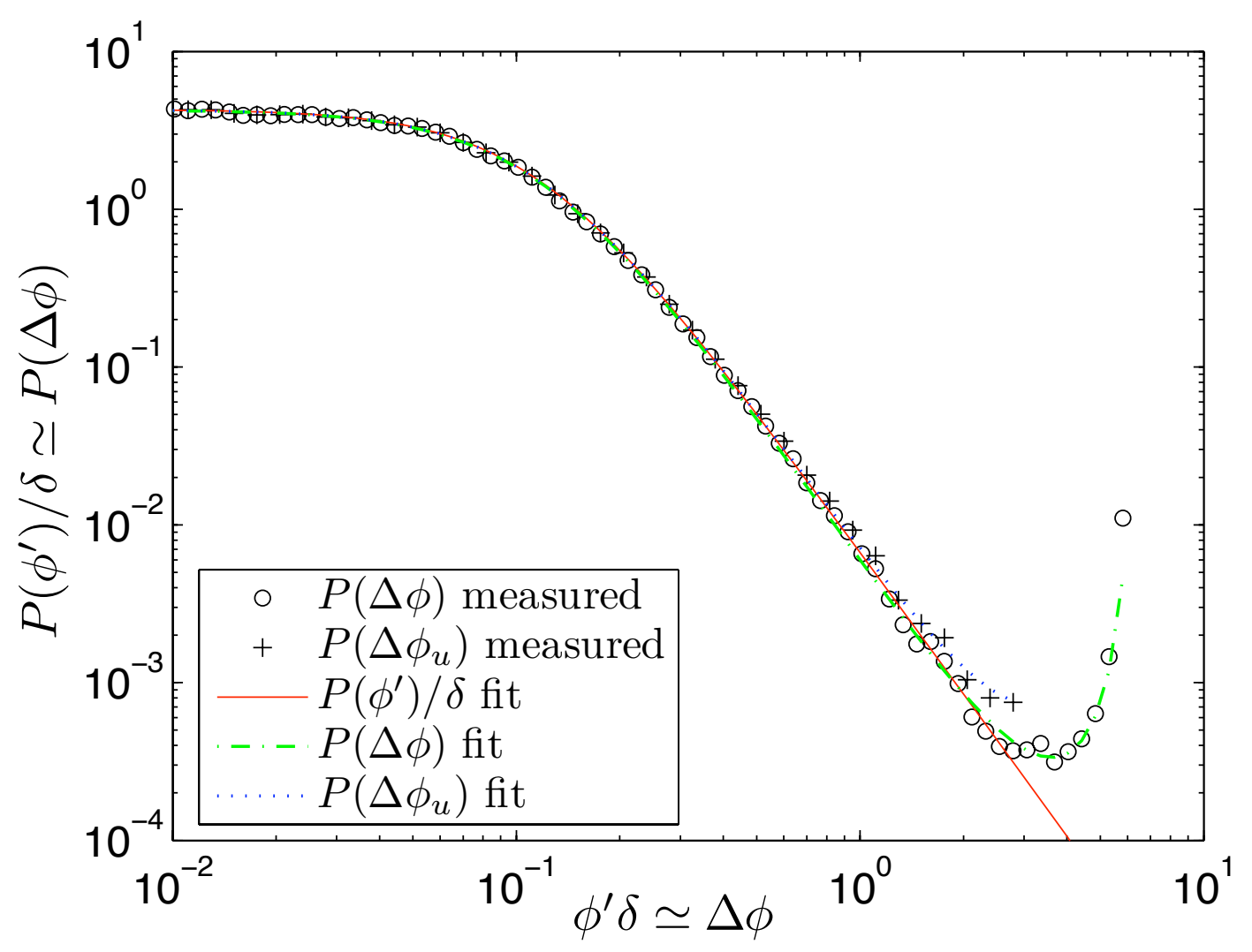

$\Delta \phi:$ Phase difference $\in(-2 \pi, 2 \pi]$

$\Delta \phi_{u}$ : Unwrapped phase difference $\in(-\pi, \pi]$ 


\section{Higher Phase Derivatives}

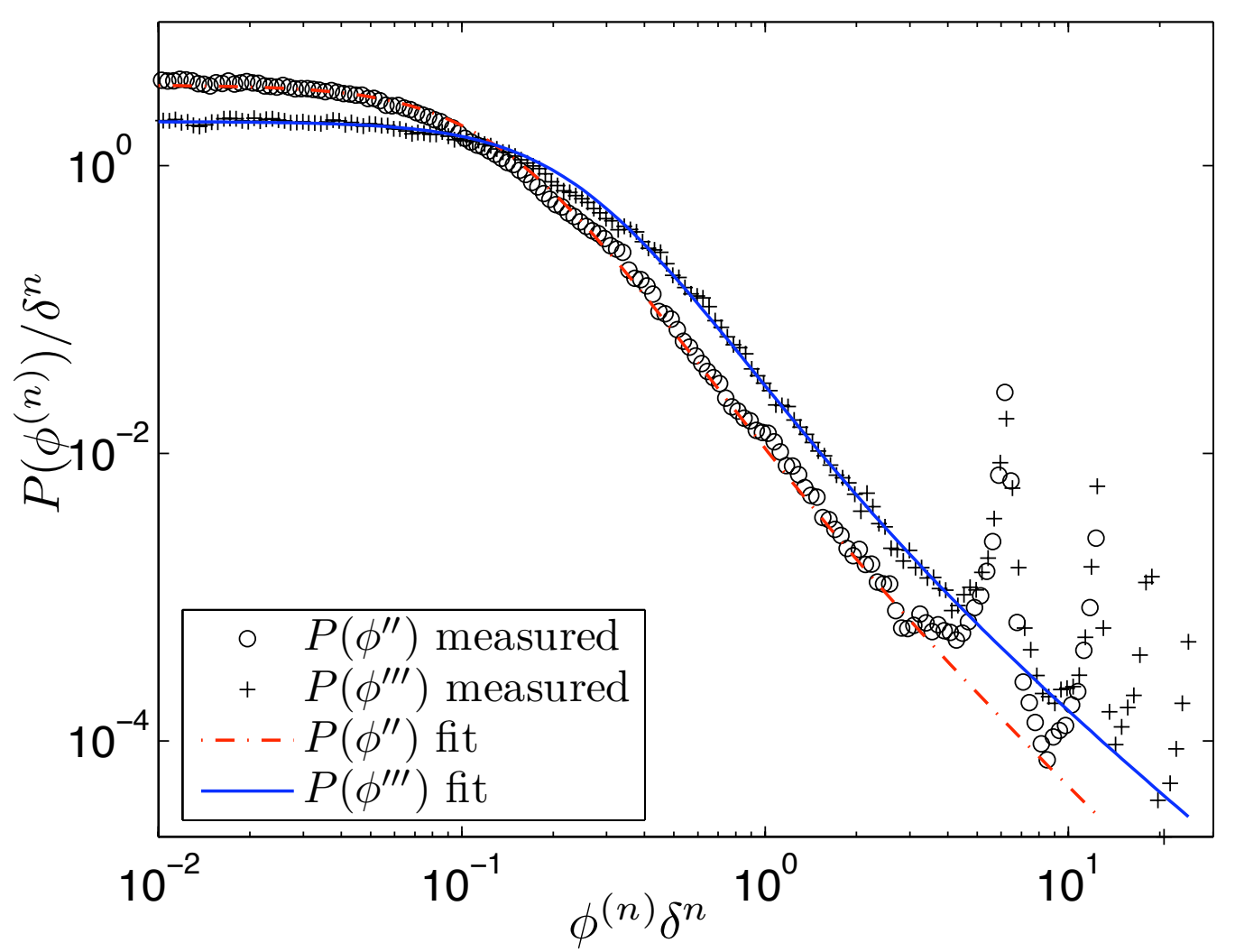

Fitting Parameters:

Coefficients of Taylor series of field correlation function Universal behavior for $n^{\text {th }}$ derivative: slope $=-(1+2 / n)$ 


\section{Phase Difference Correlation}

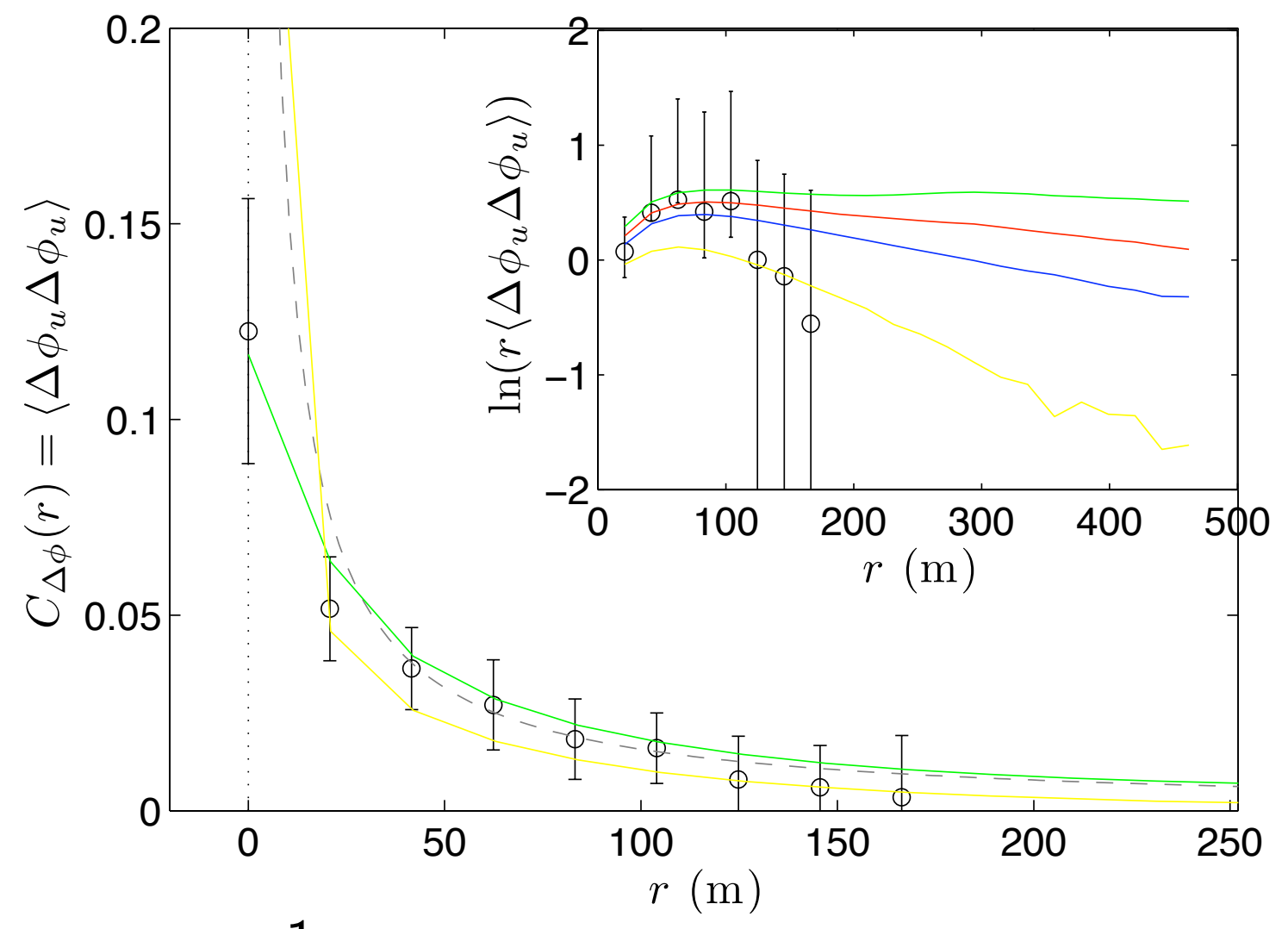

Correlation function $\approx \frac{1}{r} e^{-r / 2 \ell}$ 